\title{
Antibacterial Activity of Beetroot Peel and Whole Radish Extract by Modified Well Diffusion Assay
}

\author{
Hafsa Maqbool $^{1 *}$, S. Visnuvinayagam ${ }^{2}$, A. A. Zynudheen ${ }^{3}$, \\ M. P. Safeena ${ }^{1}$ and Sathish Kumar ${ }^{3}$
}

${ }^{1}$ Fish Processing Technology, Kerala University of Fisheries \& Ocean studies (KUFOS), Panangad, Cochin 682 506, India

${ }^{2}$ Micorbiology, Fermentation and Biotechnology Division, Central Institute of Fisheries Technology (CIFT), Matsyapuri, Willingdon Island, Cochin 682 029, India

${ }^{3}$ Fish Processing Division, Central Institute of Fisheries Technology (CIFT), Matsyapuri, Willingdon Island, Cochin 682 029, India, India

*Corresponding author

\section{Keywords}

Beetroot peel, Radish, Agar well diffusion, MIC and MBC

Article Info

Accepted:

15 December 2019 Available Online: 20 January 2020

\section{A B S T R A C T}

Screening of antimicrobial compound from waste and low cost plant material would be better alternative material for synthetic food preservatives. Hence, in the present study, beetroot peel and whole radish was chosen. Beet root peel extract (BPE) and Whole radish extract (WRE) was prepared using water and screened for the antibacterial compound against various food borne pathogen using modified well diffusion assay. Then the minimum inhibitory concentration (MIC) and minimum bactericidal concentration (MBC) level was identified for the various food pathogens. Results showed that direct crude extract of both beetroot peel and radish having the antibacterial activity against Staphylococcus aureus, Escherichia coli, Salmonella typhi and Vibrio cholera. WRE was more effective than the BPE. It is concluded that antibacterial activity of the plant derived material is truly depends upon the extraction method and the type of solvent used for extraction. Two to four fold higher concentration of water based extraction is needed to get the effect of fat solvent based extraction. BPE and WRE can be a promising source of antimicrobial agents to control the specific food borne pathogens. The modified well diffusion assay can be used for the initial screening of large number of unfiltered the plant extract and combined method of well diffusion assay with MIC would be more suitable procedure to identify the exact antibacterial activity of the crude unfiltered plant materials. 


\section{Introduction}

Frequent reports of food borne illness were observed in humans due to consumption of fish and shell fish. Bacteria such as Staphylococcus aureus, Salmonella, Vibrio cholerae and Escherichia coli are causative agent for the disease outbreak (Novoslavskij et al., 2016). Moreover, isolation of multidrug resistant pathogenic bacteria was regularly reported in the seafood by the researchers (Visnuvinayagam et al., 2015; 2016; 2017; 2018). In order to overcome the problem, seafood industries are forced to use the synthetic antimicrobials to limit the growth of seafood borne pathogens (Wong et al., 2006). Since, most of the chemical preservatives are proven hazardous and carcinogen on their long term use, most of the chemicals are under strict regulations (Bialonska et al., 2010; Carocho et al., 2015). Recently, plant materials like spices, aromatic herbs, fruit peels and other natural materials have been screened for the potential antimicrobial activities (Viji et al., 2015; Visnuvinayagam et al., 2019). Therefore, a growing commercial interest on plant-derived nontoxic antimicrobials can control bacterial and fungal growth in food systems (Gyawalli and Ibrahim, 2014). The present study is an attempt to make use of the low cost plant materials as an economic alternative for the costly synthetic chemicals, which can be used in the industry to control the pathogenic bacteria. So, two plants materials viz., Beetroot peel (Beta vulgaris) and white radishes (Raphanus sativus) were chosen. Since, the beet root peel was discarded as a waste, so the present study was aimed for the utilization of waste and screening of the biomolecules. Similarly, radish was chosen owing to it's availability throughout the year at cheaper rate.

Beetroot (Beta vulgaris)belonging to the Chenopodiaceae family is well known powerful vegetable with respect to its antimicrobial properties and has great application in food industry as a natural colorant due to its betalain content (Kujala et al., 2000; Canadanovic-Brunet et al., 2011). Moreover, beetroot peel also possesses several bioactive compounds depicting the strong antimicrobial and antioxidant activity in comparison to other vegetable peel extracts (Miller et al., 2000). Kujala et al., (2002) has documented that the total phenolics content in beetroot decreases in the order peel $(50 \%)$, crown (37\%), and flesh (13\%).

White radish (Raphanu ssativus) belongs to the Brassicaceae family contains phenolic acid, flavonoids and anthocyanins that act as potential antimicrobials. It is well documented that radish has many medicinal properties. Radish has strong antimicrobial property due to presence of isothiocyanates (ITCs) compounds such as methylthio-3butenyl isothiocyanate, allyl-isothiocyanate, benzyl isothiocyanate, and phenethyl isothiocyanate (Dufour et al., 2015).

Most of the previous studies on the plant extracts were carried out based on the organic solvent. So, in order to find the economic alternative for industrial application towards the control of food borne pathogens the nonsolvent extraction method was followed in the present study to screen most of the food borne pathogen.

\section{Materials and Methods}

\section{Preparation of extract}

Fresh beetroot peel and white radish were purchased from the market in Kochi and washed thoroughly with potable water. The raw materials were separated into two halves; first half of beetroot peel (Beta vulgaris) and white radish (Raphanus sativus) was ground for 2 min to obtain the crude juice and juices 
were passed through muslin cloth in order to remove the coarse particles (Satish et al., 2016). The second half of the raw materials were sliced and kept in solar drier at $50^{\circ} \mathrm{C}, 24$ hr. for dry power preparation. Then the dried materials were ground into powder, sieved and stored in air tight container for further use.

\section{Protein concentration}

The crude extract of both beet root peel and whole radish were subjected to Kjeldahl protein assay in order to find the protein concentration and both extracts were stored at $-20^{\circ} \mathrm{C}$ as a small volume aliquot was needed for further antibiogram analysis.

\section{Modified well diffusion assay}

Antibiogram was carried as per CLSI (2012) standard agar well diffusion technique with slight modification against $S$. aureus, Escherichia coli, S.typhi, V. cholera, A. hydrophila and $P$. aeruginosa. In the present study, instead of Mueller Hinton Agar (MHA) plate, a selective media plate for each of the bacteria was used (Table 1).Pre-set specific media was prepared and 5-6 mm diameter well was made using cork borer (\#LA 373, HiMedia), then the bottom of the agar was sealed with sterile molten agar to avoid leakages.

Test bacterial culture was inoculated into Brain Heart Infusion (BHI) Broth and incubated at $37^{\circ} \mathrm{C}$ for $2-4 \mathrm{hrs}$. The grown cultures were adjusted with sterile normal saline solution until 0.5 Mc Farland standard turbidity appeared. Sterile cotton swab was immersed into test culture and spread over the plate. Beetroot peel and radish crude extracts of $100 \mu \mathrm{l}$ were added into the each well along with the control and the plates were incubated at $37^{\circ} \mathrm{C}$. The initial concentration of the BPE and WRE were $4.38 \mathrm{mg} / 100 \mu \mathrm{L}$ and 0.6 $\mathrm{mg} / 100 \mu \mathrm{L}$, respectively. After $24 \mathrm{hrs}$ halo zone was measured using standard antibiotic zone scale (PW 096, Hi Media).

Minimum Inhibitory Concentration (MIC) and Minimum Bactericidal Concentration (MBC)

MIC and MBC of crude extracts was determined by tube dilution method (EUCAST, 2003). The initial concentration of the BPE and WRE were $43.8 \mathrm{mg} / \mathrm{mL}$ and 6 $\mathrm{mg} / \mathrm{mL}$ respectively. Serial dilution of the BPE and WRE extracts were carried out in test tubes. $1 \mathrm{~mL}$ Mueller Hinton Broth (MHB) was added into all the tubes, then $1 \mathrm{~mL}$ of crude extract was added into the first test tube and mixed thoroughly and transferred the 1 $\mathrm{mL}$ into second test tube; similarly, $1 \mathrm{~mL}$ was serially diluted ( 2 fold dilution ratio) up to $11^{\text {th }}$ tube. Then $50 \mu \mathrm{l}$ of bacterial culture containing $5 \times 10^{5} \mathrm{cfu}$ were added into all the test tubes and all the test tubes were incubated at $37^{\circ} \mathrm{C}$ for overnight for $\mathrm{MIC}$ and $\mathrm{MBC}$ determination.

After determination of MIC, later a loopful of inoculum taken from tubes having no bacterial growth and streaked on Mueller Hinton Agar (MHA) plates and incubated for further $24 \mathrm{~h}$ at $37{ }^{\circ} \mathrm{C}$. The lowest concentration that can destroy all the bacteria is considered as MBC.

\section{Results and Discussion}

In the present study, crude extract of beetroot peel and whole radish were prepared and the antimicrobial activity was initially checked with the modified well diffusion assay, later it was confirmed by the MIC and MBC for the better application in the food industry. Based on the Kjeldahl protein assay, the concentration of protein in the extract was measured. The protein concentration of the BPE and WRE were $43.8 \mathrm{mg} / \mathrm{mL}$ and 6 $\mathrm{mg} / \mathrm{mL}$ respectively. 


\section{Modified well diffusion assay}

In the present study, initially the BPE and WRE was filter sterilized and the antibiogram activity was checked with the standard Muller Hinton Agar (MHA) medium with the specific bacterial cultures. But, no inhibition was found against any of the bacteria by both the extracts. It may be due to all the antimicrobial bio-molecule would be attached to the filter. Since, the extract was prepared from the water; it may be still intact with the filter. So, the well diffusion assay has to be carried out in the unfiltered material. But, in the unfiltered material a high level of other bacterial flora would grow around the well. So, in order to find the antimicrobial activity of unfiltered material in the present study a well diffusion assay was carried out with slight modification i.e., instead of Mueller Hinton Agar, a specific media for the specific bacteria was prepared and the wells were made in the plate. So, the crude extracts were directly placed in agar well without filtration (unsterilized). Since, it is specific to each bacteria, it will allow only the inoculated bacteria to grow Eg. Mannitol salt agar was used for the $S$. aureus. Mannitol salt agar specifically will allow the growth of $S$. aureus due to higher concentration of salt and restricts the other bacterial growth (Table 1). So, pre-set plate was prepared and well was made with 5-6 mm diameter then the bottom was sealed with sterile molten agar. S. aureus culture of $0.5 \mathrm{McF}$ Farland concentration was spread over the plate. Then, the crude extract was placed in the well and the inhibition was measured after the overnight incubation at $37^{\circ} \mathrm{C}$. Similarly, other bacteria were also tested with this method, the details of the media with concern bacteria are listed in the table 1 .

In the present study, one set of crude extract was directly prepared from the plant; other set of extract was prepared directly by adding the water in the powder of the beetroot peel and whole radish. Results showed that direct crude extract of both beetroot peel and radish has the antibacterial activity against Staphylococcus aureus, Escherichia coli, Salmonella typhi and Vibrio cholera (Figure 1). This finding was in agreement with the result of Pavlovic et al., (2013); who reported the crude extract of beetroot has been the most effective against Staphylococcus aureus and $K$. pneumoniae. Ironically, the powder (powder dissolved in water) of beetroot and radish did not exhibit any antibacterial activity. It may due to the loss of activity while preparing the powder. i.e., beetroot and radish powder was exposed to the drying temperature of $50^{\circ} \mathrm{C}$ that might have caused the loss of activity. Pavlovic et al., (2013) also stated that loss of antibacterial was observed while extracting the bio-molecule at temperature more than $50^{\circ} \mathrm{C}$; they also suggested that low temperature in the extraction process would prevent the thermal deprivation of bioactive compounds.

Crude beetroot peel showed the inhibition zone ranging from $12.61 \pm 0.17 \mathrm{~mm}$ to $14.66 \pm 0.25 \mathrm{~mm}$. Highest zone of inhibition $(14.66 \pm 0.25 \mathrm{~mm})$ was found against $E$. coli and the minimum $(12.61 \pm 0.17 \mathrm{~mm})$ inhibition zone was found against Salmonella typhi (Table 2 and Figure 1).Narender et al., (2018) also reported the highest inhibition zone by beetroot against $E$. coli and $S$. aureus was 26 $\mathrm{mm}$ and $25 \mathrm{~mm}$ respectively. But, in the present study, the zone size was less compared to other previous report, it may be due to water was used for the extraction of the bio-molecule, it is much less efficient to extract the bio-molecule using the fat solvent extraction. Nisa et al., (2015) also has reported the antimicrobial activity of beetroot dye against the $E$. coli and other specific microorganisms like Salmonella spp., Staphylococcus aureus, Pseudomonas spp., yeast and moulds. Reason for the antibacterial 
activity of beetroot peel may be due to the presence of bioactive compounds such as betanin and isobetanin (John et al., 2017).

Similarly crude whole radish extract showed the inhibition range from $13.10 \pm 0.53 \mathrm{~mm}$ to $21.33 \pm 0.17 \mathrm{~mm}$. The radish extract was effective against the $S$. aureus with the maximum zone of inhibition (21.33 \pm 0.17 $\mathrm{mm})$ and depicted the lowest zone $(13.10 \pm 0.53 \mathrm{~mm})$ of inhibition against the $V$. cholera. Ahmad et al., (2012) has reported the lesser values of zone inhibition (7-9 $\mathrm{mm}$ ) by crude extract of radish as compared to our findings. Reason of antimicrobial activity of radish can be attributed to presence of flavonoids which are found to be effective against a wide range of microorganisms; presence of complex soluble proteins may react with the bacterial cell wall thus causes antibacterial activity (Parekh et al., 2008).

The overall results indicated that the crude whole radish extract was more effective than the beetroot peel extract. Based on the present observations it is depicted that the antibacterial activity of the plant derived material truly depends upon the extraction method and the type of solvent used for extraction. In the present study no antimicrobial activity was observed for the both extracts against the $P$. aeruginosa and $A$. hydrophila.

\section{MIC and MBC}

Among the four bacteria, lowest (better) value was observed for the beetroot extract on Pseudomonas aeruginosa that is $13.13 \pm 4.38$ mg compared to other three pathogens (Table 2). Similarly, the lowest (better) MBC value was observed for the Pseudomonas aeruginosa i.e., $13.13 \pm 4.38$ compared to other three pathogens. Based on the MIC and MBC value the order of susceptibility was observed for the BPE as follows Pseudomonas aeruginosa $<$ Aeromonas hydrophila $<$ Staphylococcus aureus and Salmonella typhi. The present study results are in agreement with the findings of Vulic et al., (2015) reports. Baydar et al., (2004) also reported that the beetroot extract exhibited antibacterial activity against Staphylococcus aureus (MIC $=0.75 \mathrm{mg} / \mathrm{ml}$. In the present study, it was observed that, a weak antimicrobial activity was found against Escherichia coli (MIC $=1.5 \mathrm{mg} / \mathrm{ml}$ ) and Pseudomonas aeruginosa (MIC $=4.5 \mathrm{mg} / \mathrm{ml}$ ) i.e., higher amount of BPE is needed to control the pathogens. Inhibitory behaviour of beetroot peel may be attributed to presence of phenolic compounds that exhibit antimicrobial activity e.g. carvacrol, oxygenated derivatives (thymol methyl ether) and its precursor $s p$-cymene and $\gamma$-terpinene (Baydar et al., 2004).

Compared to previous report the higher (Poor) MIC and MBC value was observed for the both beet root peel and whole radish extract. The reason may be due to that water was used in the present study for the extraction of the bio-molecule. Approximately double time concentration of MIC and MBC was noticed in the present study. Based on the MIC and MBC value of the crude whole radish extract it was observed that the $P$. aeruginosa was susceptible compared to other three pathogens. $0.11 \pm 0.04$ mg of crude radish extract was able to inhibit the $P$. aeruginosa and $0.23 \pm 0.08 \mathrm{mg}$ was able to completely destroy the same bacteria.

In the present study, some of the bacteria showing susceptible to modified well diffusion assay, but were not able to detect in the MIC and MBC i.e., E. coli was able to show the susceptibility in the modified well diffusion assay, but were not detected in the MIC and MBC assay. Similarly, organism like Pseudomonas and Aeromonas showed susceptibility in the MIC and MBC assay, but 
was not inhibited in the modified well diffusion assay. The ambiguity of result may be due to some contaminant may grow in the modified well diffusion assay and some organism may grow in the broth or the biomolecule in the BPE can be dissolved in the broth (MIC) so the contact of the biomolecule is possible in the water medium; in case of well diffusion the contact is not possible. So, based on this observation, to identify the exact antimicrobial activity, a combined method of well diffusion assay and MIC would be better result. Since, the modified method is easy and not need use the filtration process it can be recommend for the initial screening of the more number of plant extract.

Table.1 Specific media's used for the growth of bacteria

\begin{tabular}{|l|l|l|}
\hline S. No. & Name of the Bacteria & Specific Media \\
\hline $\mathbf{1}$ & Staphylococcus aureus (ATCC-25923) & Mannitol Salt agar (MSA) \\
\hline $\mathbf{2}$ & Escherichia coli(ATCC-10536) & Eosin methylene blue (EMB) agar \\
\hline $\mathbf{3}$ & Salmonella typhi(ATCC-9150) & Hektoen enteric agar (HEA) \\
\hline $\mathbf{4}$ & Vibrio cholera & Thiosulfate citrate bile salt sucrose (TCBS) agar \\
\hline $\mathbf{5}$ & Aeromonas hydrophila (ATCC-35654) & Trypticase soya agar with Ampicillin \\
\hline $\mathbf{6}$ & $\begin{array}{l}\text { Pseudomonas aeruginosa (ATCC- } \\
\text { 10145) }\end{array}$ & $\begin{array}{l}\text { Trypticase soya agar with Cephalothin-sodium } \\
\text { Fusidate-Cetrimide (CFC) supplement }\end{array}$ \\
\hline
\end{tabular}

Table.2 Zone of inhibition zone for the BPE and WRE in modified well diffusion assay

\begin{tabular}{|l|c|c|}
\hline Pathogenic microorganism & \multicolumn{2}{|c|}{ Inhibition zone (mm) } \\
& $\begin{array}{c}\text { Beetroot peel } \\
\text { extract (BPE) }\end{array}$ & $\begin{array}{c}\text { Whole radish extract } \\
\text { (WRE) }\end{array}$ \\
\hline Staphylococcus aureus & $13.15 \pm 0.13$ & $21.33 \pm 0.17$ \\
\hline Escherichia coli & $14.66 \pm 0.25$ & $16.00 \pm 0.20$ \\
\hline Salmonella typhi & $12.61 \pm 0.11$ & $20.34 \pm 0.02$ \\
\hline Vibrio cholera & NI & $13.10 \pm 0.03$ \\
\hline Aeromonas hydrophila & NI & NI \\
\hline Pseudomonas aeruginosa & NI & NI \\
\hline
\end{tabular}

NI- No inhibition, Results are given as mean \pm standard deviation

Table.2 Minimum Inhibitory Concentration and Minimum Bactericidal Concentration of BPE and WRE against pathogenic microorganism

\begin{tabular}{|l|c|c|c|c|}
\hline \multirow{2}{*}{$\begin{array}{c}\text { Pathogenic } \\
\text { microorganism }\end{array}$} & \multicolumn{2}{|c|}{$\begin{array}{c}\text { Beetroot peel extract (BPE) } \\
\text { mg/100 } \boldsymbol{\mu L}\end{array}$} & \multicolumn{2}{c|}{$\begin{array}{c}\text { Whole radish extract(WRE) } \\
\mathbf{m g} / \mathbf{1 0 0} \boldsymbol{\mu L}\end{array}$} \\
\cline { 2 - 5 } & MIC & MBC & MIC & MBC \\
\hline S. aureus & $26.25 \pm 8.75$ & $35 \pm 0.0$ & $2.3 \pm 0.8$ & $2.3 \pm 0.8$ \\
\hline S. typhi & $26.25 \pm 8.75$ & $35 \pm 0.0$ & $2.3 \pm 0.8$ & $2.3 \pm 0.8$ \\
\hline P. aeruginosa & $13.13 \pm 4.38$ & $13.13 \pm 4.38$ & $1.1 \pm 0.4$ & $2.3 \pm 0.8$ \\
\hline A. hydrophila & $26.25 \pm 8.75$ & $26.25 \pm 8.75$ & $2.3 \pm 0.8$ & $2.3 \pm 0.8$ \\
\hline
\end{tabular}

Results are given as mean \pm standard deviation 
Figure.1 Modified well diffusion assay for the unfiltered crude extract

Where= Inhibition zone against I.S. aureus; II .E.coli, III. S. typhi, IV.V. cholerae A: beetroot peel powder in distilled water B: crude extract of radish $\mathrm{C}$ : crude extract of beetroot peel D: radish powder in distilled water E: distilled water as control
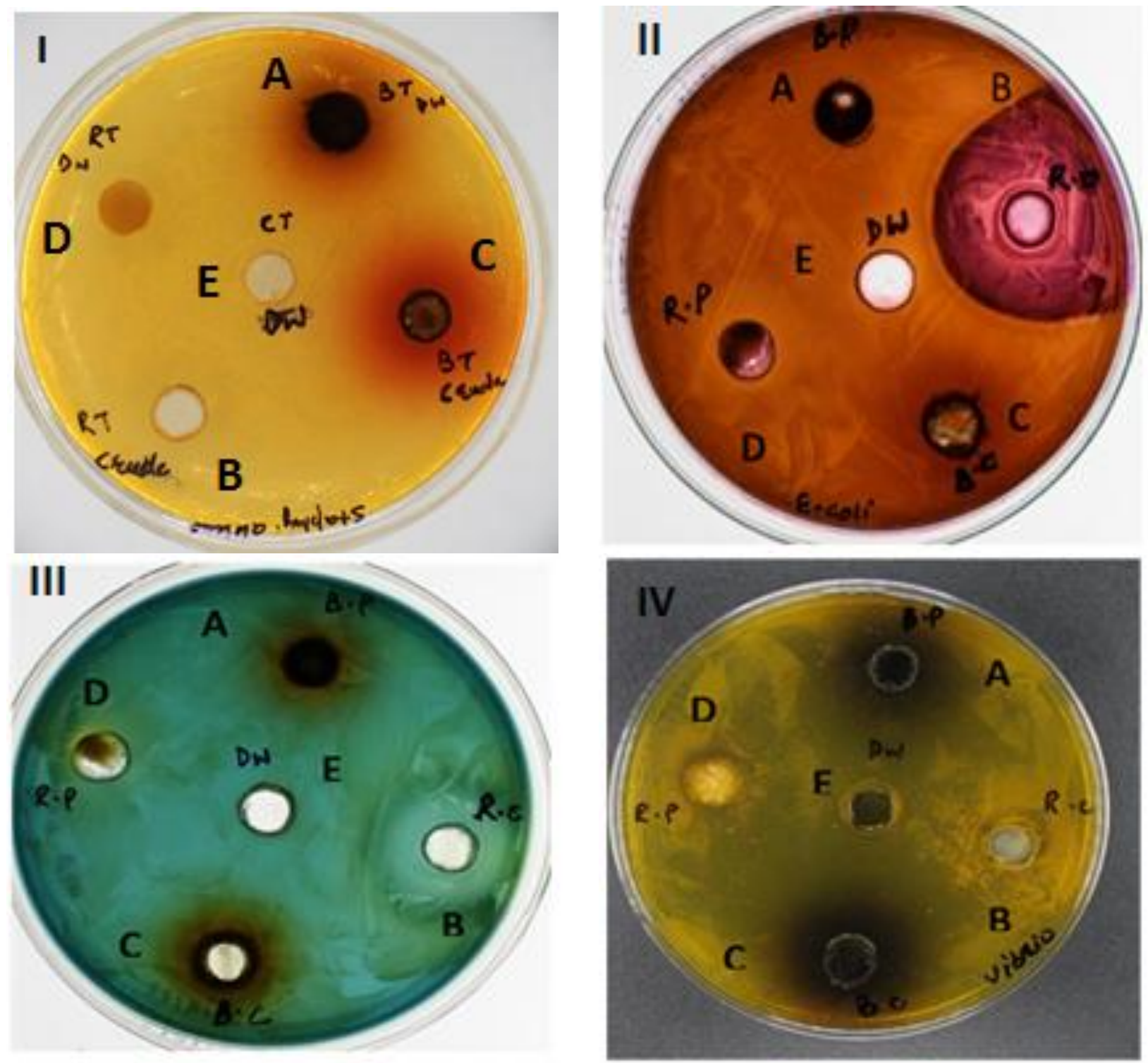

Based on the experimental outcome, it can be concluded that both the beetroot peel and whole radish can be a promising source of antimicrobial agents but much need to be explored regarding the activity of solvent free natural extracts. Since the modified well diffusion assay is rapid and economic and

suitable of the most of the crude extract analysis it will be a more useful to screen the large number of plant extract. The combined method of well diffusion assay with MIC would be more suitable procedure to identify the exact antibacterial activity of the crude unfiltered plant materials. 


\section{Acknowledgement}

Authors are highly thankful to Prof. A. Ramachandran, Vice-Chancellor Kerala University of Fisheries \& Ocean Studies (KUFOS) and Dr. Ravishankar, C.N., Director, ICAR-Central Institute of Fisheries Technology, Cochin for providing valuable support to carry out this research work.

\section{References}

Ahmad, F., Hasan, I., Chishti, D. K. and Ahmad, H. 2012.Antibacterial Activity of Raphanus Sativus Linn.seed extract. Glob J. Med. Res. 12(11)

Baydar, H., Sagdic, O., Ozkan, G. and Karadogan, T. 2004. Antibacterial activity and composition of essential oils from Origanum, Thymbraand Saturejaspecies with commercial importance in Turkey.Food Control15, 169-172

Bialonska, D., Ramnani, P., Kasimsetty, S.G., Muntha, K.R., Gibson, G.R. and Ferreira, D.,

2010. The influence of pomegranate byproduct and punicalagins on selected groups of human intestinal microbiota. Int. J. Food Microbiol. 140, 175-182.

Canadanovic-Brunet, J. M., Savatovic, S. S., Cetkovic, G. S., Vulic, J. J., Djilas, S. M., Markov, S. L. and CzechDragoljub, D. 2011. Antioxidant and antimicrobial activities of beet rootpomace extracts. J. Food Sci. 29 (6)575-585.

Carocho, M., Morales, P. and Ferreira, I.C.F.R. 2015. Natural food additives: Quo vadis? Trends Food Sci. Technol. 45 (2), 284-295.

Clinical and Laboratory Standards Institute, 2012. Performance Standards for Antimicrobial Disk Susceptibility Tests, Approved Standard, 7th ed., CLSI document M02-A11. West Valley Road,
Suite 2500, Wayne, Pennsylvania 19087, USA.

Dufour, V., Stahl, M. and Baysse, C. 2015. The antibacterial properties of isothiocyanates. Microbiol. 161, 229243

European Committee for Antimicrobial Susceptibility Testing, 2013. Determination of minimum inhibitory concentration (MICs) of antibacterial agents by broth dilution. EUCAST discussion document of the European Society of Clinical Microbiology and Infectious Diseases (ESCMID) CMI, 9, $1-7$.

Fu, Y., Sarkar, P., Bhunia, A.K. and Yao, Y. 2016. Delivery systems of antimicrobial compounds to food.Trends Food Sci. Technol. 57, 165-177.

Gyawalli, R. and Ibrahim, S. A. 2014.Natural products as antimicrobial agents.Food Control 46, 412-429.

John, S., Monica, J. S., Priyadarshini, S., Sivaraj, C. and Arumugam, P. 2017. Antioxidant and Antibacterial activities of Beta vulgaris L. Peel extracts. Int. J. Pharma. Res. Health Sci. 5 (6) 1974-79.

Kujala, T. S., Loponen J.M., Kika, K. D. and Pihlaja, K. 2000.Phenolic and betacyanins in red beetroot; distribution and effect of cold storage on the content of total phenolic and three individual compounds.J. Agri. Food Chem. 48, 5338-5342.

Kujala, T. S., Vienola, M. S., Klika, K. D., Loponen J. M. and Pihlaja, K. 2002. Betalain and phenolic compositions of four beetroot (Beta vulgaris) cultivars, Eur. FoodRes. Technol.214, 505-510.

Miller, H. E, Rigelhof, F., Marquart, L., Prakash, A., Kanter, M. 2000.Antioxidant content of whole grain breakfast cereals, fruits and vegetables.J. Am. Coll. Nutr. 19, 312319.

Narender, R., Rajakumari, M. Sukanya, B. 
and Harish, S. 2018. Antimicrobial activity on peels of different fruits and vegetables. J. Pharma Res. (1) 1-7.

Nisa, A., Saeed, K., Hina, S., Zahra, N., Mazhar, S., Kalim, I. and Syed, Q. 2015. Nutritional, antioxidant, microbiological and toxicological studies on red dye extracted from red beet roots (Beta vulgaris). Res. J. Chemical Sci.5(4) 1-6.

Novoslavskij, A., Terentjeva, M., Eizenberga, I., Valciņa, O., Bartkevičs, V. and Bērziņš, A., 2016. Major foodborne pathogens in fish and fish products: a review. Annals of microbiology, 66(1), pp. $1-15$

Parekh, J. and Chanda, V. 2008. Antibacterial activity of aqueous and alkoholic extracts of 34 Indian medicinal plants against some Staphylococcus species. Turk. J. Biol. 32, 63-71.

Pavlovic, R., Mladenovic, J., Maskovic, P. and Acamovic-Dokovic, G. 2013. Biological activity of beetroot extracts. $2^{\text {nd }} \quad$ Conference VIVUSEnvironmentalism, Agriculture, Horticulture, Food protection and processing. Biotechnical centre Naklo, Strahinj 9, NakloSolvenia.

Sathish, K. K., Nagalakshmi, K. and Venkateshwarlu, G. 2016. Preservative effect of solvent free natural spice extracts on tuna fillets in chilled storage at $4{ }^{\circ} \mathrm{C}$ : Microbial, biochemical and sensory attributes. Int. J. Fish. Aquat. Studies 4(6) 20-24.

Viji, P., Binsi, P.K., Visnuvinayagam, S., Bindu, J., Ravishankar, C.N. and Gopal, T.K.S., 2015. Efficacy of mint (Menthaarvensis) leaf and citrus (Citrus aurantium) peel extracts as natural preservatives for shelf life extension of chill stored Indian mackerel. J. Food Sci. Technol. 52(10), pp.6278-6289.
Visnuvinayagam S., Joseph T.C., Murugadas, V., Chakrabarti, R., and Lalitha, K.V., 2015. Status on methicillin resistant and multiple drug resistant Staphylococcus aureus in fishes of Cochin and Mumbai coast, India. J. Environ. Biol. 36(3):571.

Visnuvinayagam, P., Viji, P., Murthy, L.N., Jeyakumari, A. and Sivaraman, G.K., 2016. Occurrence of faecal indicators in freshwater fishes of Navi Mumbai in retail outlets.Fish.Technol. 53; 334-338.

Visnuvinayagam S., Murthy L.N., Viji P, Sivaraman G.K., 2017. Study on retail fish markets: Possible occurrence and transmission of emerging pathogen from faecal indicators. J. Environ. Biol. $38,465-470$.

Visnuvinayagam S., Murthy L.N., Parvathy U., Jeyakumari A., Adiga T.G., Sivaraman G.K., 2018. Detection of multi drug resistant bacteria in retail fish market water samples of Vashi, Navi Mumbai. Proceedings of the National Academy of Sciences, India Section B: Biological Sciences, 89(2):559-64.

Visnuvinayagam, S., Murthy, L.N., Jeyakumari, A., Parvathy, U., Anandan, R., Sivaraman, G.K. and Ravishankar, C.N., 2019. Combined effect of zinc oxide nano particle incorporated chitosan for better antimicrobial activity towards wound healing. J. Environ.Biol. 40, 691-697.

Vulic, J. J., Tatjana N. C ebovic’b, Jasna, M. C. B., Gordana S. C., Vladimir, M. C., Sonja, M. D. and Vesna, T. T. S. 2014. In vivo and in vitro antioxidant effects of beetroot pomace extracts. J. Funct. Foods 6, 168-175.

Wong, S.P., Leong, L. P. and William Koh, J. H. 2006.Antioxidant activities of aqueous extracts of selected plants.Food Chem. 99, 775-783. 


\section{How to cite this article:}

Hafsa Maqbool, S. Visnuvinayagam, A. A. Zynudheen, M. P. Safeena and Sathish Kumar. 2020. Antibacterial Activity of Beetroot Peel and Whole Radish Extract by Modified Well Diffusion Assay. Int.J.Curr.Microbiol.App.Sci. 9(01): 1222-1231. doi: https://doi.org/10.20546/ijcmas.2020.901.135 